\title{
A constituição de domicílios unipessoais em condomínio específico para idosos
}

\section{Constitution of single-person households in a condominium for older adults \\ La constitución de hogares unipersonales en condominio específico para ancianos}

\author{
Elen Ferraz Teston'; Sonia Silva Marcon ${ }^{I I}$
}

\begin{abstract}
RESUMO: O objetivo do estudo foi conhecer a percepção do idoso que vive só com relação à constituição dos domicílios unipessoais. Estudo exploratório, de abordagem qualitativa, realizado com 20 residentes do Condomínio do Idoso do município de Maringá, Paraná. Os dados foram coletados no mês de fevereiro de 2012, mediante entrevistas semiestruturadas realizadas no próprio condomínio e submetidos à análise de conteúdo. Alguns dos idosos consideram que a constituição do domicílio unipessoal é oriunda da separação ou morte do companheiro, outros reconhecem como uma oportunidade de recomeço. Além disso, morar só foi relacionado à autonomia, o que gera insegurança para o idoso em situações de adoecimento. Entretanto, alguns referiram que, por residirem no Condomínio, sentem-se aliviados. Portanto, faz-se necessária a atuação do enfermeiro junto a esta população com o intuito de reduzir os fatores de risco, estimulando a adoção de ações de autocuidado com vistas à manutenção da saúde.

Palavras-Chave: Idoso; enfermagem; habitação; promoção da saúde.
\end{abstract}

\begin{abstract}
The objective was to study the perceptions of older adults living alone as to the constitution of single-person households. This qualitative, exploratory study involved 20 elderly residents of the Condomínio do Idoso in Maringá, Paraná, Brazil. Data collected in February 2012 by semi-structured interviews conducted at the condominium were then subjected to content analysis. Some of the older adults regarded the single-person home as arising from separation or partner's death, while others recognized it as an opportunity for a new start. In addition, living alone was related to autonomy, which creates insecurity in older adults in situations of illness. However, some said that, as they lived in the condo, it was a relief. Accordingly, it is necessary for nurses to work with this population to reduce risk factors and encourage self-care actions with a view of maintaining health.
\end{abstract}

Keywords: Older adults; nursing; housing; health promotion.

RESUMEN: El objetivo fue estudiar la percepción del anciano que vive solo en relación con el establecimiento de los hogares unipersonales . Estudio exploratorio, cualitativo, realizado con 20 residentes del Condominio del Anciano de Maringá , Paraná-Brasil . Los datos fueron recogidos en febrero de 2012, a través de entrevistas semiestructuradas realizadas en el propio condominio y sometidos al análisis de contenido. Algunos de los ancianos sienten que la constitución de la casa unipersonal es oriunda de la separación o fallecimiento del compañero, otros lo reconocen como un nuevo comienzo. Por otra parte, la vida solo estaba relacionado con la autonomía, lo que crea inseguridad para el anciano en situaciones de enfermedad. Sin embargo, algunos dijeron que, por vivir en el condominio, se sienten aliviados. Por lo tanto, es necesario el trabajo de las enfermeras en esta población con el fin de reducir los factores de riesgo, estimulando la adopción de acciones de autocuidado con el fin de mantener la salud.

Palabras Clave: Anciano;enfermería; habitación;promoción de la salud.

\section{INTRODUÇÃO}

Este artigo constitui um recorte da dissertação de mestrado intitulada Condomínio para idosos: implicações para a saúde e o cuidado de enfermagem nessa nova modalidade habitacional, pertencente ao Programa de Pós-Graduação em Enfermagem da Universidade Estadual de Maringá (UEM).

O interesse em realizar este estudo foi decorrente de uma visita realizada à recente modalidade habitacional, no município de Maringá-Paraná, intitulada de Condomínio do Idoso. A partir disso, surgiram reflexões e inquietações relacionadas à constituição dos domicílios nesse Condomínio.

Sabe-se que a constituição de domicílio unipessoal é influenciada pela autonomia e condição geral de saúde do idoso ${ }^{1}$. Frente a isso, o presente estudo teve como objetivo conhecer a percepção do idoso que vive só com relação à constituição dos domicílios unipessoais.

${ }^{I}$ Enfermeira da Estratégia Saúde da Família no município de Jandaia do Sul. Doutoranda na Universidade Estadual de Maringá, Paraná, Brasil. E-mail: elen-1208@hotmail.com.

IIEnfermeira. Doutora em Filosofia da Enfermagem. Professora da Graduação e da Pós-Graduação em Enfermagem da Universidade Estadual de Maringá. Coordenadora do Núcleo de Estudos, Pesquisa, Assistência e Apoio à Família. Maringa, Paraná, Brasil. E-mail: soniasilva.marcon@gmail.com. 


\section{REVISÃO DE LITERATURA}

Os Condomínios para Idosos surgem como uma nova modalidade habitacional para idosos de baixa renda e se constituem em uma estratégia de garantia do direito à moradia, principalmente para àqueles que vivem em condições precárias. Diferentemente do que ocorre em asilos e casas de repouso, os moradores desta modalidade habitacional são independentes, pagam aluguel (simbólico) por sua moradia e têm autonomia para entrar e sair quando bem entendem, além de decidirem sobre a organização do condomínio de forma coletiva ${ }^{2,3}$. As moradias podem ser ocupadas por idosos que vivem só e por aqueles que possuem companheiros também idosos.

Trata-se uma modalidade habitacional recente no Brasil3, o que justifica a escassez de estudos. Já internacionalmente, teve início na década de $1950 \mathrm{com}$ o aumento da população idosa ${ }^{4,5}$. Diante da tendência recente de redução do número de filhos, aumento do número de divórcios, melhora nas condições de saúde da população idosa e aumento da longevidade, é de se esperar que ao longo dos anos haja um crescimento dos domić́lios unipessoais, ou seja, cresça o número de idosos vivendo só 6 .

Diante disso, pretende-se com o presente estudo contribuir com a construção da enfermagem gerontológica, favorecendo o planejamento de estratégias de cuidado, a partir da percepção do idoso que vive só, com relação a fatores influentes nessa condição.

\section{Metodologia}

Estudo exploratório, de abordagem qualitativa, realizado junto a idosos residentes no Condomínio do Idoso do município de Maringá, Paraná,o qual foi implantado em agosto de 2010, e conta com 40 domicílios que abrigam 50 moradores, dos quais 28 moram sozinhos.

Os dados foram coletados no mês de fevereiro de 2012, mediante entrevistas realizadas no próprio domicílio. As entrevistas, após o consentimento dos participantes, foram gravadas em gravador do tipo digital, com duração média de 20 minutos, e norteadas por um roteiro semiestruturado composto por duas partes. A primeira foi constituída pela seção I (composta por 10 questões de caracterização sociodemográfica) do Instrumento BOAS (Brazil old age schedule), utilizado na pesquisa matricial, traduzido e validado no Brasil ${ }^{7}$. A segunda parte foi constituída por três questões norteadoras, elaboradas pelos próprios autores, com base nos objetivos do estudo: $\mathrm{O}$ que representa para o $\mathrm{Sr}(\mathrm{a})$ morar sozinho? Fale sobre isso. Em geral, o Sr gosta de morar sozinho? Fale sobre as vantagens e desvantagens de morar sozinho.

Participaram do estudo 20 dos 28 idosos que residem em domicílio unipessoal no condomínio. Nenhum outro critério além do fato de residir só foi adotado para inclusão ou exclusão no estudo. Os participantes, portanto, foram os primeiros 20 idosos abordados, visto que as informações coletadas até então, além de estarem se repetindo, já eram suficientes para responder aos objetivos do estudo.

Para análise dos dados, as entrevistas foram transcritas na íntegra e, após, submetidas à análise de conteúdo modalidade temática. Na primeira fase foram realizadas leituras das falas, com vista a levantar os pontos relevantes para o objetivo do estudo. $\mathrm{Na}$ fase de exploração do material, procedeu-se à codificação dos dados. No tratamento dos resultados, foi realizada a categorização, que consiste na classificação dos elementos segundo suas semelhanças e por diferenciação, com o posterior reagrupamento em função de características comuns ${ }^{8}$. A análise dos dados deu origem a duas categorias: Para onde a vida me levou; Para viver sozinho é preciso saúde e amigos.

O desenvolvimento do estudo ocorreu em conformidade com o preconizado pela Resolução $\mathrm{n}^{\mathrm{o}}$ 196/96 do Conselho Nacional de Saúde, e foi aprovado pelo Comitê Permanente de Ética em Pesquisa Envolvendo Seres Humanos, da Universidade Estadual de Maringá (Parecer no. 70912011). Todos os sujeitos assinaram o Termo de Consentimento Livre e Esclarecido, dando anuência à sua participação, em duas vias. Para a diferenciação dos sujeitos e preservação de sua identidade, foram utilizados os seguintes códigos: a letra $\mathrm{F}$ identificando o sexo feminino e a letra $\mathrm{M}$ o sexo masculino, seguido da idade do entrevistado.

\section{Resultados E Discussão}

Dos 20 idosos em estudo, 15 são mulheres, com faixa etária variando entre 63 e 86 anos, sendo três a média de número de filhos. Quanto à escolaridade, 16 dos idosos possuem 4 anos de estudo e quatro deles nenhuma escolaridade. Com relação à renda, todos os idosos recebem um salário mínimo.

A análise temática dos dados permitiu a identificação de duas categorias que são descritas a seguir:

\section{Para onde a vida me levou}

Estudo de revisão sobre a decisão de morar sozinho aponta algumas variáveis que contribuem para a constituição do domicilio unipessoal, entre elas o sexo, a idade, a escolaridade, a residência urbana ou rural, a renda, a condição de saúde, além do tipo de relação familiar estabelecido ao longo dos anos ${ }^{6,9}$.

Predomina entre os idosos em estudo, a constituição do domicílio unipessoal após os 60 anos, o que pode indicar uma imposição contingenciada pela morte do companheiro ou separação, conforme evidenciado nos depoimentos.

Eu morava com meu marido. Mas aí veio a idade e levou ele de mim. (F77) 
Morávamos em uma casinha bem pequena [...] Mas aí a idade veio mais cedo para mim, porque sou 12 anos mais velha que ele. Ele arrumou uma mulher mais jovem e eu passei a morar sozinha....velha e sozinha. (F 68)

Eu e meu marido éramos companheiros um do outro, em tudo, mas ele teve um derrame fulminante, então fiquei sozinha. (F73)

Observa-se, no penúltimo depoimento, o estabelecimento de uma relação negativa entre o processo de envelhecimento e a constituição do domicílio unipessoal, como se representassem dois fatores interligados e inerentes um ao outro. Diante disso, os profissionais de saúde, em especial enfermeiros, necessitam considerar estas especificidades no planejamento de ações de cuidado junto aos idosos em geral. Sugere-se um preparo especial do enfermeiro quanto à abordagem do processo de envelhecimento junto ao idoso, de modo a promover a reflexão sobre as mudanças constantes e individuais em todas as fases da vida e reconhecimento necessário para lidar com as perdas e buscar novas aquisições durante todo o processo, a fim vivenciá-lo de forma natural e saudável ${ }^{10}$.

A constituição do domicílio unipessoal também constitui opção para alguns idosos.

Eu fui casado muito tempo, mas aí a mulher começou com uma modernidade de querer mandar na casa?! Foi ai que eu decidi me separar e procurar um lugar para mim, para viver do jeito que eu acho certo.... Antes só do que mal acompanhado! (M 69)

Eu moro sozinho porque eu gosto de fazer as coisas do meu jeito. Eu estou namorando agora, e ela quer morar junto, mas eu não quero, porque cada um tem um sistema de vida. Eu não troco minha liberdade... (M82)

Morar sozinho é dar asas para as pessoas. Hoje eu não quero ser preso não, viver no cativeiro dos filhos, quero fazer as coisas do meu jeito, ir onde eu quiser sem ter alguém controlando. Os idosos também precisam de liberdade, até mesmo para manter sua qualidade de vida. (M73)

Observa-se, nesses últimos depoimentos, a associação entre viver só e a manutenção da autonomia/ liberdade, o que coaduna com resultado encontrado em estudo de base populacional, realizado em Belo Horizonte, cujos achados apontaram que morar só permite definir melhor o seu espaço e decidir sobre a forma de organizar a casa, os horários, sem deixar, contudo, de manter relações com parentes e amigos ${ }^{11}$.

Ainda relacionado à autonomia/liberdade, estudo realizado junto a idosos, do interior do Rio Grande do Sul, constatou que para eles a autonomia e o poder de decisão, dentro do próprio domicílio, representam fator fundamental para a sua qualidade de vida e preservação de sua dignidade. Quando lhes são impostas decisões, a despeito de como devem agir e do que fazer, os idosos sentem que perdem a liberdade ${ }^{12,13}$. Frente a isso, verifica-se a importância dos profissionais de saúde reforçarem as orientações relacionadas à eliminação de fatores de risco para o desenvolvimento/agravamento de doenças crônicas, com vistas à manutenção da autonomia e preservação da independência, fatores que são fundamentais para o idoso poder morar sozinho.

A constituição do domicílio unipessoal pode também representar uma oportunidade de recomeçar e atribuir novo sentido à vida.

[...] eu já morei com meus filhos e eu não gostei! Fui me acostumando a fazer o serviço da casa enquanto todos estavam na rua e fui me fechando para as coisas do mundo... Vim morar sozinho... E aqui as coisas funcionam da minha maneira, é como se eu tivesse começado uma nova fase da minha vida... (F72)

Eu morava com a minha filha. Às vezes minha filha pegava o meu dinheirinho e dizia que eu tinha que ajudar em casa, mas chegou uma hora que eu estava bancando tudo por lá! Estou começando minha vida de novo, porque já sofri demais com filho e marido bêbado. (F67)

O velho que pode morar sozinho tem mais é que ir, porque a gente está velho, mas precisa viver, se divertir, conhecer outras pessoas. (F76)

Os idosos precisam perceber o quão bom é ter sua casa, e que a velhice está na pele, no corpo, mas o coração da gente e a cabeça, se quisermos, podem nos conservar jovens por toda vida. Muitas vezes a decisão de morar sozinho pode significar a oportunidade de um recomeço... para mim foi isso. (F83)

Observa-se que esta percepção de recomeço está relacionada a oportunidades até então negadas pelas relações estabelecidas ao longo da vida. Em estudo europeu, realizado no Reino Unido junto a idosos, que residem em Condomínio específico para idosos, constatou-se que esse tipo de modalidade habitacional proporciona um estilo de vida positivo, e oferece oportunidades não vivenciadas anteriormente e que influenciam diretamente na qualidade de vida do idoso ${ }^{14}$.

\section{Para viver sozinho é preciso saúde e amigos}

Os possíveis desequilíbrios na situação geral de saúde, como por exemplo, as sequelas, temporárias ou permanentes, que podem limitar o exercício de atividades de vida diária, foram as principais desvantagens apontadas com relação à constituição do domicílio unipessoal.

Ah, uma coisa que me dá muito medo e acho muito ruim de morar sozinha - é porque uma hora fica doente e não tem quem cuida da gente! (F63)

Eu fico preocupada quando penso que, Deus me livre e guarde, a gente fica ruim de noite, com uma doença e a gente está sozinha. (F78) 
O lado ruim de morar sozinho é que chega uma hora que não consegue mais fazer todas as coisas sozinha, principalmente quando fica doente. (F86)

Enquanto eu estou me virando sozinha e fazendo tudo, as coisas estão bem.... mas o que eu nem gosto de pensar, é se um dia eu ficar de cama... (F64)

A independência comprometida devido a ocorrência de adoecimento constitui um fator gerador de insegurança para alguns idosos que vivem só, o que corrobora resultados de um estudo realizado junto a idosos da região metropolitana de Belo Horizonte, com o objetivo de determinar os fatores associados à incapacidade funcional entre idosos ${ }^{11}$. Portanto, faz-se necessário investir em intervenções de saúde que visem à promoção do autocuidado, de forma a tornar o indivíduo corresponsável pelo próprio cuidado o que reduz significativamente o desenvolvimento de doenças e/ou complicações que comprometam a rotina diária de atividade ${ }^{15,16}$.

Apesar da desvantagem relatada anteriormente, observa-se que o fato de viverem em um condomínio é percebido por certos idosos como um fator favorável à constituição de domicílios unipessoais.

Mesmo morando sozinho, a gente se sente segura porque havendo qualquer problema tem os vizinhos. Depois que me mudei para cá, arrumei uma companheira, amiga e acompanhante para me ajudar nas horas que preciso [...]. (F74)

Esses dias passei mal e pedi para a vizinha do lado ir junto comigo no postinho. Sorte que, aqui, mesmo morando sozinho, a vizinhança se ajuda. (F71)

Morar sozinho, mas ter esses vizinhos [...] aqui, morando no mesmo pátio, é bom. Qualquer apuro a gente corre ali. (M77)

A estrutura física do Condomínio permite a manutenção da individualidade do idoso, já que cada um possui seu domicílio, entretanto, permite também interação entre os moradores por contar com um ambiente comum a todos (praça, Academia da Terceira Idade e a horta comunitária). Evidencia-se que, mesmo residindo só, alguns idosos se sentem mais aliviados por terem sempre alguém por perto para ajudá-los e que compreenda, por experiência própria, essa necessidade.

Estudo realizado em São Paulo, também com idosos residentes em condomínio, apontou, entre os aspectos positivos de viver em um conjunto habitacional específico para idosos, o companheirismo entre os moradores frente a situações de dificuldades e necessidade de apoio ${ }^{2}$. Nesse mesmo sentido, estudo europeu também evidenciou os benefícios oriundos do estabelecimento de vínculos entre os idosos moradores de condomínio especial e a sua influência na qualidade de vida do idoso ${ }^{4}$.

Por fim, vale destacar que no condomínio onde o estudo foi realizado, caso o idoso apresente alguma alteração em sua condição de saúde e se torne dependente de cuidados, deixará de atender a um dos quesitos básicos para residir nesse domicílio, e, dessa forma, será encaminhado para um serviço do município que conta com cuidadores. Diante do exposto, reforça-se a necessidade de investimentos, por parte dos profissionais de saúde, no planejamento e implementação de ações de autocuidado voltadas para o idoso que reside só, a fim de manter sua autonomia e independência, já que constituem fatores diretamente relacionados ao tipo de arranjo domiciliar constituído.

\section{Conclusão}

Partindo-se dos resultados obtidos na investigação, parte dos idosos considerou que a constituição do domicílio unipessoal é oriunda da separação ou morte do companheiro. Outros reconheceram como uma escolha e oportunidade de recomeço. Constatouse também que a constituição do domicilio unipessoal foi relacionada diretamente com a manutenção da autonomia, o que gera insegurança ao idoso em situações de adoecimento. Entretanto, certos idosos referiram que, por residirem em um Condomínio específico e cercado por outros idosos, também vivenciam as mesmas inseguranças, sentem-se mais aliviados por terem sempre por perto alguém com quem contar.

No tocante aos desafios e potencialidades na constituição dos domicílios unipessoais, faz-se necessário que os profissionais de saúde, em especial o enfermeiro, atuem junto a esta população com o intuito de reduzir os fatores de risco, estimulando a adoção de ações de autocuidado com vistas à manutenção da saúde.

Como limitação do estudo, considera-se o fato de as informações terem sido obtidas em um único Condomínio do Idoso. Sugere-se a realização de novas pesquisas, em outros condomínios, a fim de comparar e/ou confirmar os resultados encontrados.

\section{REFERÊNCIAS}

1.Ramos JLC, Menezes MR, Meira EC. Idosos que moram sozinhos: desafios e potencialidades do cotidiano. Rev baiana enferm. 2010; 24(13): 43-54.

2.Alves SID. Um modelo de moradia para idosos: o caso da Vila dos Idosos do Pari-São Paulo (SP). Cad Tem Kairós Gerontol [Internet].2010 [citado em 25 ago 2012];8:195-213. Disponível em: http://revistas.pucsp. br/index.php/kairos/article/view/6922/5014

3.Teston EF, Rossi RM, Marcon SS. Utilização de serviços de saúde por residentes em um Condomínio exclusivo para idosos.Rev esc enferm USP.2013;47:1125-32.

4.Evans S. That lot up there and us down here: social interaction and a sense of community in a mixed tenure UK retirement village. Ageing \& Society. 2009; 29(1): 199-216. 5.Bernard M, Bartlam B, Sim J, Biggs S. Housing and 
care for older people: life in an English purpose-built retirement village. Journals Cambridge. 2011; 27: 555-78. 6.Camargos MCS, Rodrigues RN, Machado CJ. Idoso, família e domicílio: uma revisão narrativa sobre a decisão de morar sozinho. Rev bras estud popul. 2011; 28(1): 217-30. 7.Veras R, Dutra S. Perfil do idoso brasileiro. Questionário Boas. Rio de Janeiro: UnATI/ UERJ; 2008.

8.Caregnato RCA, Mutti R. Pesquisa qualitativa: análise de discurso versus análise de conteúdo. Texto contexto - enferm.2006; 15: 679-82.

9.Dias DSG, Carvalho CS, Araújo CV. Comparação da percepção subjetiva de qualidade de vida e bem-estar de idosos que vivem sozinhos, com a família e institucionalizados. Rev bras geriatr gerontol. 2013; 16(1):127-38. 10.Souza RF, Matias HA, Bretãs ACP. Reflexões sobre envelhecimento e trabalho. Ciênc saúde colet. 2010; 15: 2835-43.

11.Giacomin KC, Peixoto SV, Uchoa E, Lima-Costa MF. Estudo de base populacional dos fatores associados à incapacidade funcional entre idosos na Região Metro- politana de Belo Horizonte, Minas Gerais, Brasil. Cad Saúde Pública.2008; 24:1260-70.

12.Falcade BL, Leite MT, Hildebramdt LM, Kirchner RM, Silva LAA, Gonçalves LHT. Octagenários em residências unipessoais:enfoque sobre a qualidade de vida e condições de saúde. Rev enferm UFSM. 2011;1:386-93.

13.Tavares DMS, Araújo MO, Dias FA. Qualidade de vida dos idosos: comparação entre os distritos sanitários de Uberaba-MG. Cienc cuid saúde. 2011. 10: 74-81.

14.Scharlach A, Graham C, Lehning A. The Village Model: a consumer-driven approach for aging in place. Gerontol. 2011; 52:418-27.

15.Tavares DMS, Martins NPF, Diniz MA, Dias FA, Santos NMF. Qualidade de vida de idosos com hipertensão arterial. Rev Saude Publica. 2011; 19: 438-44.

16.Honório GJS, Martins HEL, Basso JF, Alvarez AM, Meirelles BS, Santos SMA. Estratégias de promoção da saúde dos idosos no Brasil: um estudo bibliométrico. Rev enferm UERJ. 2013; 21: 121-6. 